\section{To Cheat or Not to Cheat}

\section{Gabor B. Levy}

There has been a recent uproar about falsified data in biomedical research. This occurs with some regularity, and even Congress has been aroused recently with the justification that the perpetrators and the universities where they worked had received public grant monies. The incidents may have been relatively few in numbers, but the fires have been fanned by the media. Less publicized, but perhaps more disturbing is the apparent conflict of interest spread by many new biotechnology companies. Researchers who develop and evaluate their products are frequently given substantial chunks of the companies whose products they are testing. Altogether, these are far from trivial matters, and they should be stopped. I have doubts, however, that the committees of Congress or Academe will come to grips with these problems. If politicians and administrators were truthful, they would have to declare, "We met the enemy and it was us."

These are my subjective opinions, of course, but we can agree that scientific research differs from other intellectual activity - different down to its roots. When society emerged from the dark Middle Ages, those of scientific bent gave up speculating and fantasizing about nature, and set to observing it. They followed by experimenting and by describing their results truthfully and in detail. By relying on these recorded observations, each new generation could start where the previous one left off, without having to repeat all that went before. The very foundation of experimental science is truthfulness - without truth, science is bound to collapse. This is in contrast with other activities such as social sciences e.g., economics. An economist who has never heard of Adam Smith would be considered uneducated, but this ignorance by itself would hardly be a hindrance in developing his ideas. Each generation starts anew, as it were.

It may seem pretentious to set experimental science apart in this manner. Indeed, it has been asserted that this is wrong; that there is no scientific truth at all and that all research is subjective. This can be said with some justification, but it applies only to scientific opinions and interpretations. This is surely so, but as long as the data are truthfully reported, they can always be re-interpreted and refined by future work. The reaction of the public is entirely justified when it is shocked by cheating in science, while it has learned to accommodate cheating in public

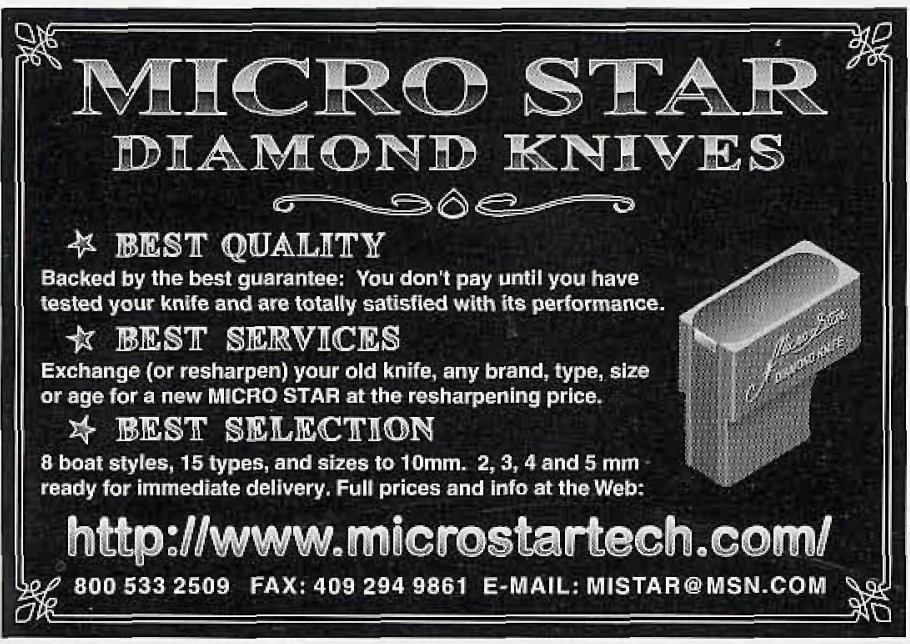

and private life.

My own experience attests to this. In my university stu: dent days, we were all imbued with the absolute necessity of truth in research. That was the real appeal in science. I wasं also spoiled by having friends in these fields, and for us, this professional behavior spilled over into our personal livesur Communication among friends was easy and reliable. It came as a shock in my first postgraduate job as a research assistant at one of our great universities to learn that honestly of this sort was limited to the lower echelons of the faculty. Depart $\approx$ ment heads and administrators were constantly scheming and plotting on assignments, budgets, and personnel matters $\frac{\bar{n}}{{ }^{*}}$ They were held in low esteem by us pygmies, but they ran theo show.

Later, in industry I found a similar situation. At manage ment meetings I was struck by the fact that the art was to guess what the truth might be, and to figure out the trick how: to get across a truthful statement in a form such that it became acceptable. These shenanigans are not limited to manage ment, I observed wild distortions and posturing by labor repre $\frac{\sqrt{\frac{5}{2}}}{2}$ sentatives as well. A friendly union official once explained thato to do any good, he had to get elected and reelected by then membership and he had to act accordingly. This is true in politics, too. You cannot accomplish anything unless you get elected, and this takes a special approach, with truthfulness and ethics hardly relevant.

In fact, public perception seems to be that truth is a cruel cutting edge, which must be rationed with discretion. It is somewhat ludicrous when in a court of law you are forced to swear "...so help me God." This does not change the person, but if by magic, it transforms the socially acceptable distortions and lies into a criminal act.

Consider that our leaders have suggested that greed is essential to the economy. Procurement officers negotiate with suppliers for jobs after retirement. Legislators often have an interest in the institutions they regulate. Bankers and lawyers scheme mergers with funds of the unit being acquired. In such an atmosphere research is handed a list of priorities by such headings as Public Image, Grants, Appropriations, Technology Transfer, Targeted Research, and Competitiveness. Truth and Ethics are near the bottom of the list. Deception and falsity are bound to spill over into research. The situation is not likely to get better, despite the stricter regulations under consideration. The jungle is too powerful.

Perhaps we should reach back and emulate the simpler and leaner times of the past. In those days, researchers were left to do research. There are serious doubts that a greedy society has the capacity and determination not to encroach on such isolated pockets of serenity and honesty. I do not know what it would take to put such a seemingly simple idea across. And I may be altogether wrong. After all, I am one of those impractical and naive science-types. I am absent-minded, too, and I lose my gloves and umbrella with some regularity.

This article is one of a series of Dr. Gabor B. Levy's essays on science and society containing thought-provoking editorials previously published in International Scientific Communications' journals. The book expresses the author's point of view on such subjects as Our Society, Our Economy, Ethics, Lawyers and the Law, Health and Medicine, Statistics, Science, Pseudoscience, Metrology, and New Directions. Size $81 / 2 " x$ 51/2". Price only $\$ 10.99$ plus $\$ 3.50$ for shipping and handling. Order now, by check or money order, as supplies are limited. International Scientific Communications, Inc., 30 Controls Drive, Shelton, CT 06484 . 


\section{Nothing tricky, nothing complex. Just rugged, reliable conventional SEMs.}

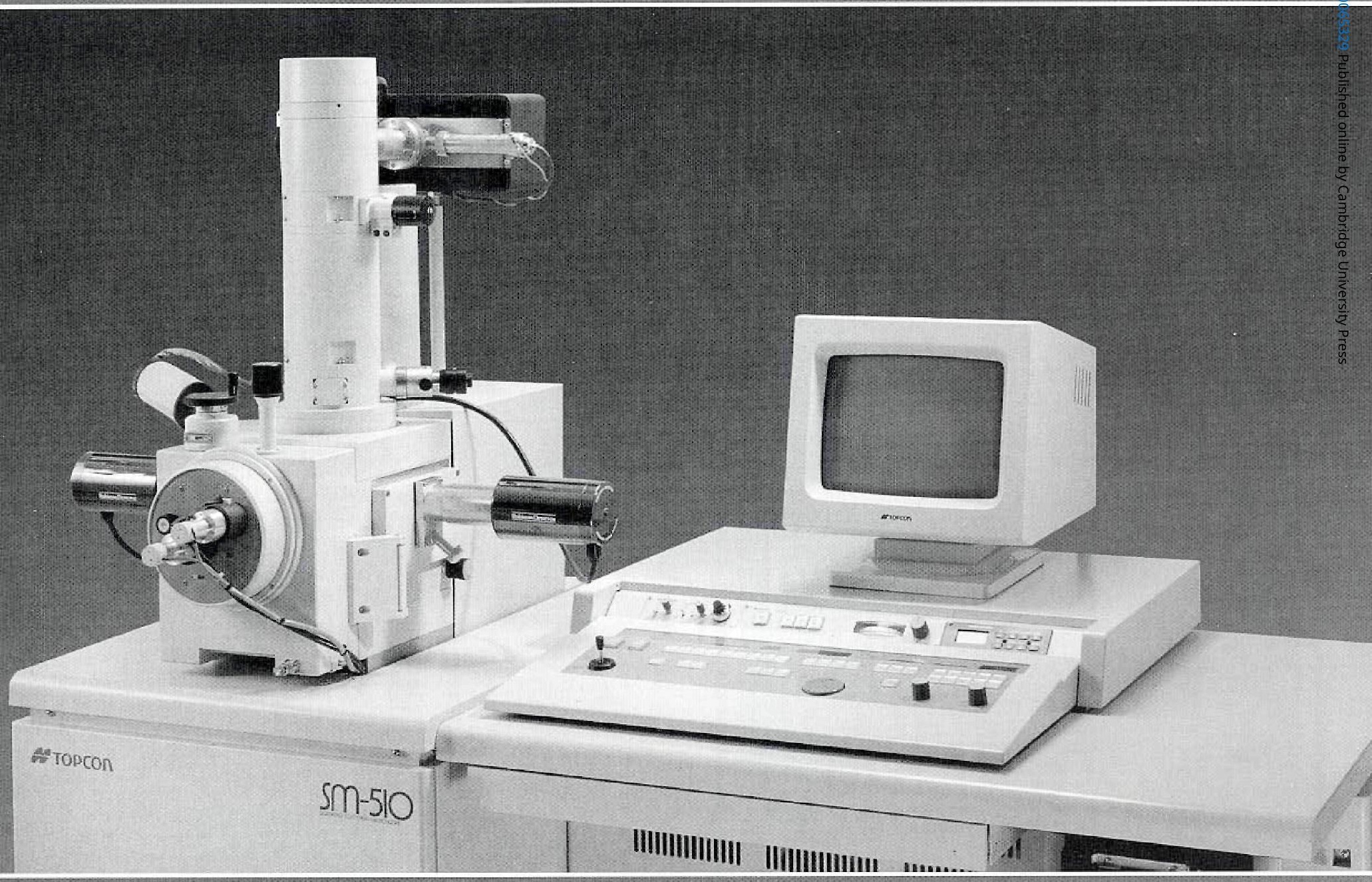

The worlds of science and industry get more complicated. No wonder that tried and true instruments, like Topcon's conventional SEMs, take on greater value.

In fact, $93 \%$ of our users say Topcon SEMs are today's greatest value. Why?

Because they are nugged, reliable, dependable, with nothing tricky or hard to learn.

For 20 years, our SEMs have been dedicated to making your world easier. They take scanning electron microscopy out of the hands of the technical elite... and put all their power in your hands instantly.

Want to know more? Call and tell us about your applications. Toll free of course. Ask for our new literature. $1-800-538-6850$.

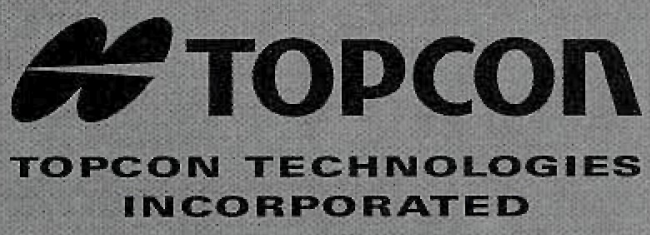




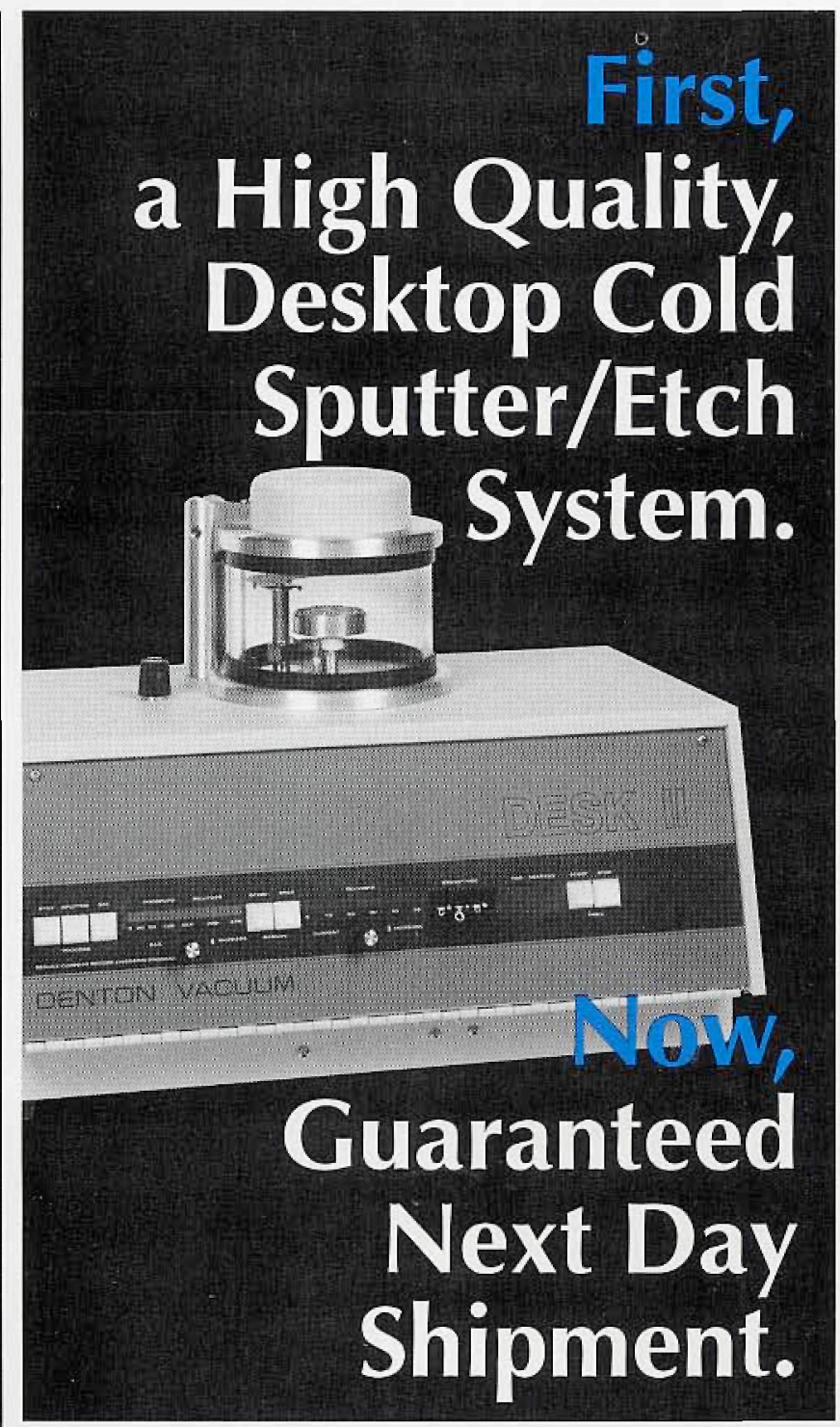

Order Denton's standard Desk II System by noon today and get guaranteed shipment tomorrow or Denton pays the freight.

The Desk II produces uniform, conductive, fine grain Au/AuPd coatings in under three minutes and is the highest quality desktop system available.

The Desk /I features:

- Automatic or manual operation

Easy to read digital vacuum and current gauges

- Optional carbon evaporation accessory

For more information, look no further than Denton... where both Quality and Delivery invite comparison.

\section{North Church St. ENTON Moorestown, NJ 08057 USA \\ WACUUIM Fax:(609) 439-9111 INC. \\ ¿ MADE IN AWERIBA}

Next day shipment must be requested at time of order.

Decades of Experience In EM Specimen Prep Equipment

\section{LIGHT REFLECTIONS}

Henrietta L. Graves

Oh, Light: that poets oft do sing,

And wise men write about,

Thou art the darkest thing I've met,

I cannot make thee out.

Thou art of luminosity

Astonishingly chary,

Thou hast no ordinary ray,

Thou'rt all extraordinary.

Enough thou art to worry saints,

When thou art once refracted;

E'en then thy vibratory pranks,

Do drive me clean distracted.

But when thou splittest thyself up Unto refraction double,

Oh, then, thy waves do me oOerwhelm In roaring seas of trouble.

Thou and the mad polariscope, In evil league combined,

Do play the most unhallowed tricks Upon my simple mind.

Thy interference figures do With my sleep interfere;

My appetite it faileth quite, Thou dost behave so queer.

Broad smutty bars of darkness sweep In dreams across by sight;

And pleochroic demons hold Mad carnivals at night.

Bisectrices and awes pierce My brain in all directions,

And oft I dream the class must be Divided into sections!

And Oh, Inclined Dispersion is Of all thy tricks the worst!

My wits when toward it they incline, Are hopelessly dispersed.

Oh, much applauded light: when first On Chaos thou didst shine,

Did not the Chaos nature get Mixed up a bit with thine?

Oh, Light: Light! Light: What mockery is here!

The blackest depths of darkest night, More luminous appear.

Depart then to the Polar lands, Be polarized forever:

We darkness choose; and let thy beams, Disturb our slumbers never.

In 1920, Dr. Norman L. Bowen discovered this poem in the effects of William Nicol of Queens University, Kingston, Ontario. No information was available about the author (Henrietta L. Graves).

Credit and thanks to Rae Vigeant, Minnesota Microscopy Society, for providing the poem.

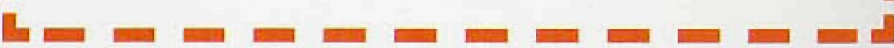




\section{Microscopy Courses}

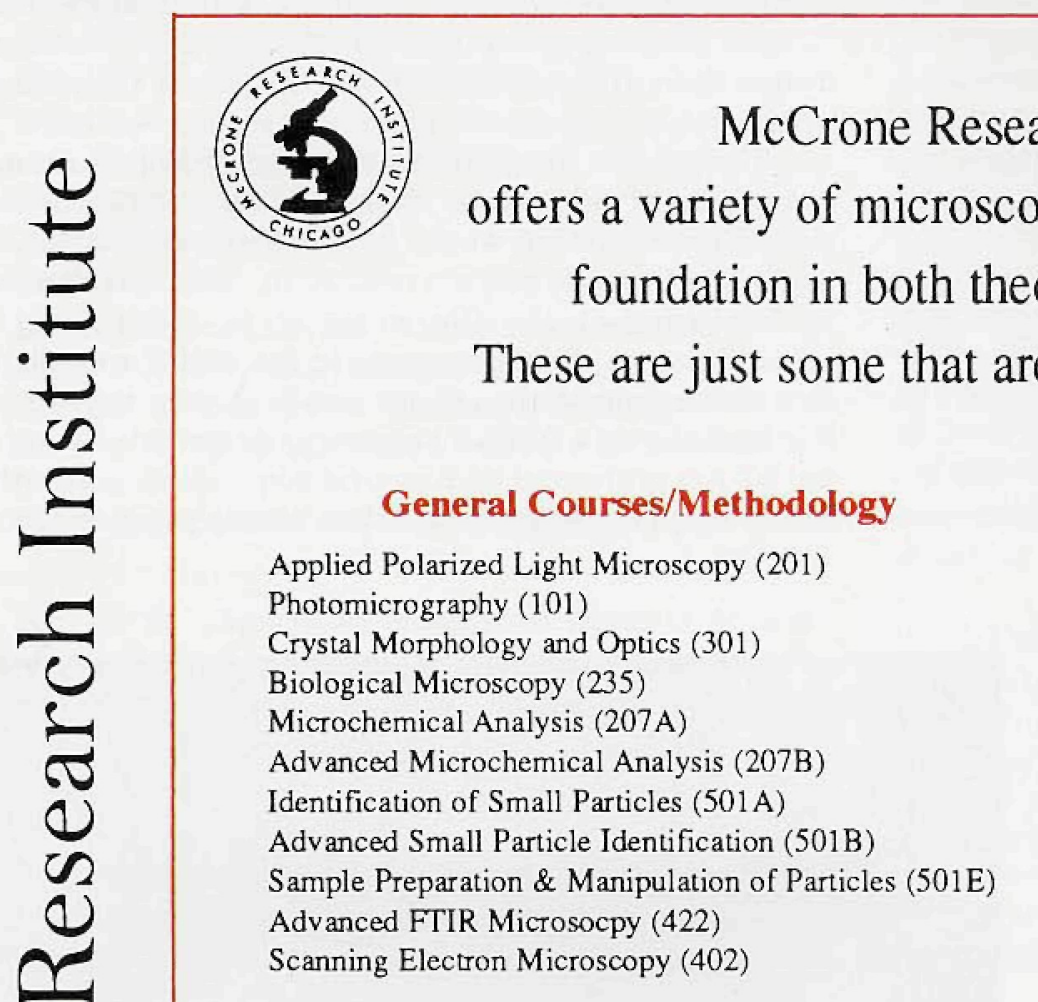

\section{Specialities}

Microscopy for Art Conservators (506)

Pharmaceutical Microscopy (503)

Polymer, Fiber \& Film Microscopy (505)

Microscopy \& Microchemistry of Polymers (505B)

Mineral Grain Identification (523)

Advanced Pollen \& Spore Identification (536B)

\section{Forensic/Materials}

Forensic Microscopy (504)

Advanced Trace Evidence (514)

Hair and Fiber Microscopy (519)

Microscopy of Explosives (522)

Microscopy of Illicit Drugs and Excipients (526)

Microscopy of Sexual Assault Evidence (535)

Microscopy of Botanical Traces (536A)

Microscopical Study of Paints and Extenders (520B)

Forensic Examination of Building Materials (527B)

Comparative Microscopy of Soil (510)

\section{Asbestos/Environmental}

Microscopical Identification of Asbestos (508A)

Advanced Asbestos Identification (508B)

Quantitative Asbestos Analysis (528)

Special Asbestos Problems (512)

Advanced Asbestos QA/QC (529)

Indoor Air Quality: Microscopy of Fungal Spores and Pollen (530)

Asbestos Fiber Counting [NIOSH 582] (516)

TEM Asbestos Analysis (407B)

\section{For Detailed Information}

Nancy Daerr, McCrone Research Institute, 2820 S. Michigan Avenue, Chicago, IL 60616-3292

Phone $\cdot 312 / 842-7100$

FAX $\cdot 312 / 842-1078$

e-mail•ndaerr@mcri.org

World Wide Web - http://www.mcri.org 